http://jmscr.igmpublication.org/home/

ISSN (e)-2347-176x ISSN (p) 2455-0450

crossref DOI: https://dx.doi.org/10.18535/jmscr/v8i1.78

Journal Of Medical Science And Clinical Research

IGM Publication

An Official Publication of IGM Publication

\title{
A retrospective analytical study of indications of cesarean section
}

\author{
Author \\ Dr Rashmi Verma \\ Associate Professor, Department of Obstetrics and Gynaecology, Katihar Medical College and Hospital, \\ Bihar, India
}

\begin{tabular}{l} 
Abstract \\
Introduction: Over the last few decades, rate of cesarean section has increased due to increase in \\
primary cesarean rate, a decrease in VBAC (Vaginal birth after cesarean section) trial, decrease in \\
operative vaginal deliveries (Forceps/Ventouse), increase in litigations, increasing facility of fetal \\
electronic monitoring, and decreasing thresholds of patients for bearing labour pains. \\
Material \& Methods: A retrospective study was carried out in 200 patients in the tertiary care hospital \\
from January 2019 to December 2019. \\
Results: Most common indication was Previous cesarean section (24.5\%), followed by Preterm Labour \\
(20.5\%), Prolonged Labour (12\%), PROM (12\%), Fetal distress (7\%). \\
Conclusion: It is recommended to reduce the number of primary cesarean section and successful VBAC \\
trials to keep the cesarean section rate to the minimum level. \\
Keywords: Previous cesarean section, Preterm Labour, Fetal distress. \\
\hline
\end{tabular}

\section{Introduction}

The number of babies delivered through cesarean section has skyrocketed worldwide and public health experts say the trend is cause for alarm. While C-section can undoubtedly be a life saving procedure, cesarean section is being dangerously overused in last few decades. According to WHO, "There is no justification for any region to have CS (cesarean section) rates higher than 10-15\%"1. Anything beyond that does not appear to reduce maternal and new born mortality rates. In USA, the rate was $27.5 \%$ in 2003 which increased to $32.8 \%$ in the year $2010^{2}$. Some Latin Americans countries were noted of having higher rates of around $40 \%^{3}$. In Britain, the rate was $21.5 \%$ in $2005^{4}$. The cesarean section rate in East Asia was above $15 \%{ }^{5}$. According to ICMR study conducted in 30 teaching hospitals in India; there is an increase in CS rates from 21.8\% in 1993-1994 to $25.4 \%$ in 1998-1999. In a study conducted in Chennai, the rate of cesarean section was as high as $50 \%{ }^{6,7}$. There are various factors involved in the rise of rate of cesarean section. There has been increase in primary cesarean section rate, a decrease in VBAC trial, decrease in operative vaginal deliveries (Forceps/Ventouse), increase in litigations, increasing facility of electronic monitoring, and decreasing threshold of patients for bearing labour pains. Data of 200 patients who underwent cesarean deliveries was reviewed for studying various factors associated with it. Cesarean section is associated with maternal postpartum morbidity, higher chances of newborns getting postpartum respiratory morbidity, less breast feeding and possibly more atopic disease $^{8}$. There are increased chances of abnormal 
placentation in future pregnancy with previous cesarean section $^{8,9}$. The objective of this study is to analyse the indications so as to find out the causes behind the rise in the rate of cesarean section and modify them so as to reduce the rate to the minimum level.

\section{Material and Method}

Retrospective analytical study of various indications of cesarean section among 200 patients was carried out at Katihar Medical College and Hospital in the department of Obstetrics and Gynaecology. Detailed history including age, obstetrics history, indications of cesarean sections, birth rate of new born to those mothers was taken. Partogram was plotted to assess the progress of labour. Continuous fetal monitoring was done in all the patients. The data was analysed to study the factors responsible for high rate of cesarean section.

\section{Results}

Table 1: Indications of Cesarean Section

\begin{tabular}{|l|c|c|c|}
\hline . S. No. & VARIABLE & FREQUENCY & PERCENTAGE \\
\hline 1 & ABRUPTIO PLACENTA & 11 & $5.5 \%$ \\
\hline 2 & BREECH & 1 & $0.5 \%$ \\
\hline 3 & ECLAMPSIA & 12 & $6.0 \%$ \\
\hline 4 & FETAL DISTRESS & 14 & $7.0 \%$ \\
\hline 5 & MSL & 1 & $0.5 \%$ \\
\hline 6 & OBSTRUCTED LABOUR & 3 & $1.5 \%$ \\
\hline 7 & PIH & 13 & $6.5 \%$ \\
\hline 8 & PLACENTA PREVIA & 2 & $1.0 \%$ \\
\hline 9 & PRETERM LABOUR & 41 & $20.5 \%$ \\
\hline 10 & PREVIOUS CS & 49 & $24.5 \%$ \\
\hline 11 & PROLONGED LABOUR & 24 & $12.0 \%$ \\
\hline 12 & PROM & 24 & $12.0 \%$ \\
\hline 13 & TWIN & 5 & $2.5 \%$ \\
\hline $\mathbf{1 4}$ & TOTAL & $\mathbf{2 0 0}$ & $\mathbf{1 0 0 \%}$ \\
\hline
\end{tabular}

During the study period, total of 1900 deliveries were performed, out of which 200 cases were delivered by cesarean section resulting in cesarean section rate of $10.5 \%$. The most common indication was Previous Cesarean Section in 49 patients $(24.5 \%)$, followed by Preterm Labour in 41 (20.5\%), Prolonged Labour in 24 (12\%), PROMin 24 (12\%), Fetal distress in 14 (7\%).

Table 2: Cases of Previous Cesarean Section

\begin{tabular}{|l|l|c|c|}
\hline S. No. & VARIABLE & FREQUENCY & PERCENTAGE \\
\hline 1 & PREVIOUS 2 CS & 21 & $42.9 \%$ \\
\hline 2 & PREVIOUS CS + SCAR TENDERNESS & 10 & $20.4 \%$ \\
\hline 3 & PREVIOUS CS + CEPHALOPELVIC DISPROPORTION & 2 & $4.1 \%$ \\
\hline 4 & PREVIOUS CS + FETAL DISTRESS & 2 & $4.1 \%$ \\
\hline 5 & PREVIOUS CS + NON-PROGRESS OF LABOUR & 4 & $8.2 \%$ \\
\hline 6 & PREVIOUS CS + OLIGOHYDRAMNIOS & 3 & $6.1 \%$ \\
\hline 7 & PREVIOUS CS + TOXAEMIA & 2 & $4.1 \%$ \\
\hline 8 & PREVIOUS CS + BREECH & 1 & $2.0 \%$ \\
\hline 9 & PREVIOUS CS + PLACENTA PREVIA & 1 & $2.0 \%$ \\
\hline 10 & PREVIOUS CS + MECONIUM STAINED LIQUOR & 1 & $2.0 \%$ \\
\hline 11 & PREVIOUS CS + TWINS & 1 & $2.0 \%$ \\
\hline 12 & PREVIOUS CS + ABRUPTION & 1 & $2.0 \%$ \\
\hline $\mathbf{1 3}$ & TOTAL & $\mathbf{4 9}$ & $\mathbf{1 0 0 . 0 \%}$ \\
\hline
\end{tabular}

As shown in Table 2 above, out of 49 cases of Previous CS cases, 42.9\% had Previous 2 CS, 20.4\% had Previous CS + Scar Tenderness, $8.2 \%$ had Previous CS + Non-Progress of Labour, 6.1\% had Previous CS + Oligohydramnios. 
Antipartum haemorrhage was an indication in 13 cases out of which 3 cases were having Placenta
Previa while rest 11 were diagnosed with Abruptio Placenta.

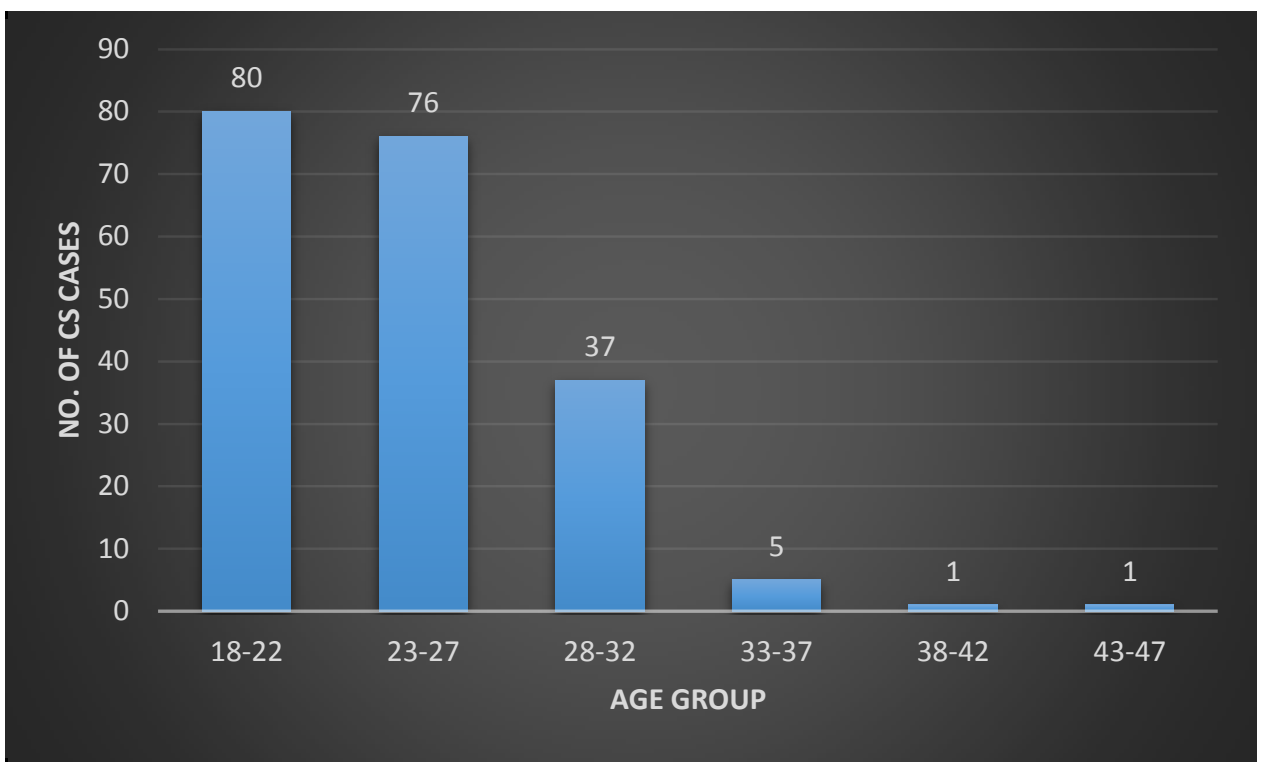

Figure 1: Age wise distribution of Cesarean Section Cases

Maximum cesarean section cases belonged to age group 18-22, followed by age group 23-27, 28-32 and 3337.
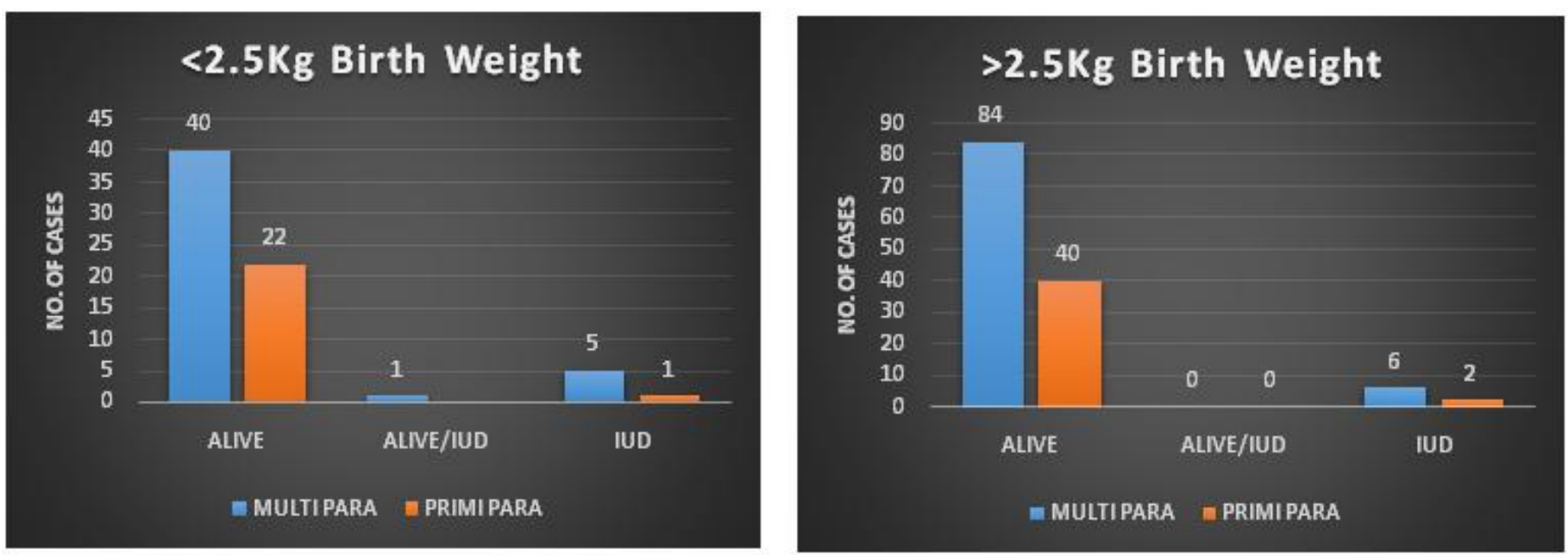

Figure 2: Outcome of CS

Figure 2 above shows that out of 65 primipara cases (irrespective of birth weight), 62 were Alive while remaining 3 were IUD cases. Similarly, out of 136 multipara cases (irrespective of birth weight), 124 were Alive and 12 were IUD cases.

\section{Discussion}

Out of 200 cases of reviewed cesarean section, most common indication was Previous cesarean section followed by Preterm Labour, Prolonged Labour, PROM. Similar results were obtained in studies conducted in USA and in South India ${ }^{10,11}$.
Previous cesarean section was the commonest indication in the study conducted in developed countries as well ${ }^{12}$. Out of 40 previous cesarean section cases, various associated risk factors were scar tenderness and contracted pelvis. There was failure of VBAC trial in 2 cases and Non-Progress of Labour in 4 cases. Other factors were Oligohydramnios, Toxaemia, Breech, Placenta Previa, Meconium Stained Liquor, Twins, Abruption. More number of VBAC trials with proper selection criteria and proper monitoring can reduce the rate of cesarean section. There are 
evidences which prove VBAC to be safer for women having prior $\mathrm{CS}^{13}$. There were 14 cases operated for cesarean because of Fetal distress with poor Bishop score. Majority of them had thick Meconium Stained Liquor, 4 cases had cord around neck which were diagnosed intraoperatively. Second common indication was Preterm Labour followed by Prolonged Labour and PROM. PROM cases were given trial of labour with proper fetal heart monitoring but were taken for cesarean section. In Breech, external cephalic version can be tried with proper precaution but planned cesarean is found to have lesser complication rate ${ }^{14,16}$. In this study, there was 1 case of primipara Breech which was operated. 3 cases presented with Obstructed Labour which needed to be operated with cesarean delivery. With age wise distribution of patients, majority of them belongs to the age group 18-30 years, while only 7 cases belonged to age group 33-47 years.

\section{Conclusion}

Rate of cesarean section has been increasing world-wide due to various reasons and indications. This can be minimized by reducing the number of primary cesarean section, proper monitoring of maternal and fetal parameters, promoting institutional deliveries and promoting VBAC in previous cesarean section cases with non-recurrent indications. The growing use of Csection for non-medical purposes could be introducing avoidable complications and it is advocated that C-section should only be used when it is medically required.

\section{Funding: None}

\section{Conflict of Interest: None}

Acknowledgements: I thank the department of Obstetrics and Gynaecology, Katihar Medical College and Hospital, for their kind cooperation and support in the conduct of the study.

\section{References}

1. World Health Organization. Appropriate technology for birth. Lancet. 1985;2 (8452):436-7.

2. Hamilton BE, Martin JA, Ventura SJ. National Vital Statistics Reports. 2011;60,1.

3. Belizan JM, Althabe F, Barros FC, Alexander S.Rates and implications of Cesarean Sections in Latin America: ecological study. BMJ. 1999;319:13971402.

4. Hamilton BE, Ventura SJ, Martin JA, Sulton PD. Priliminary births for 2004: infant and maternal health. Health E-Stats. Released, 2005.

5. Stanton CK, Holtz SA. Studies in Family Planning, 2006.

6. Kambo I, Bedi N, Dhillon BS, Saxena AC. A critical appraisal of Cesarean section rates at teaching hospitals in India. Int $\mathbf{J}$ Gynaecol Obstet.2002;79:151-8.

7. Sreevidya S, Sathiyasekaran BW. British Journal of Obstetrics and Gynaecology, 2003.

8. Tollånes MC. Increased rate of Cesarean sections--causes and consequences. Tidsskr Nor Laegeforen. 2009; 129(13):1329-31.

9. Silver RM, Landon MB, Rouse DJ, Leveno KJ, Spong CY, Thom EA et al. Risk of placenta previa and accrete to number of previous cesarean deliveries. Obtetrics \& Gynecology. 2006;107:1226.

10. Emma L, Lisbet L, Kathleen B, Christian M,Edmund F, Jessica L. Contributing Indications to the Rising Cesarean Delivery Rate. Obstet Gynecol. 2011;118(1):29-38.

11. Unnikrishnan B, Rakshith P, Aishwarya A, NithinK, Rekha T, Prasanna $P$ et al. Indications for Cesarean Section in a tertiary care Obstetric Hospital in Coastal South India. Australasian Medical Journal AMJ. 2010;3(12):821-825. 
12. Wang CP, Tan WC, Kanagalingam D, Tan HK. Why we do cesears: a comparison of trends in cesarean section delivery over a decade. Ann Acad Med Singapore. 2013;42(8):408-12.

13. Guise JM, Eden K, Emeis C, Denman MA. Vaginal birth after cesarean: new insights. Evidence Report/Technology Assessment Jorunal. 2010;(191):1-397.

14. Hofmeyr GJ, Kulier R. External cephalic version for breech presentation at term. Cochrane Database Syst Rev., 2012.

15. Leung C, Pun WC. Term breech trial. Lancet.2001;357(9251):225.

16. Hannah ME , Hannah WJ, Hewson SA, Hodnett ED, Saigal S, Willan AR. Planned cesarean section versus planned vaginal birth for breech presentation at term: a randomised multicentre trial. Term Breech Trial Collaborative Group. Lancet. 2000; 356(9239):1375-83. 